\title{
Характеристика переселенческой политики в Российской империи в 60-80-е гг. XIX в. в контексте дискурса имперских экспертов
}

\author{
Попов Е.В. \\ Филиал Омского государственного педагогического университета в г. Таре, \\ 646530, Россия, г. Тара, ул. Школьная, 69 \\ E-mail: pve83@inbox.ru
}

\begin{abstract}
Аннотация. В данной статье представлена структура переселенческого управления, а также определены основные этапы колонизационной политики с 60-х по 80-е гг. XIX в. Обозначены основные дискуссионные позиции имперских экспертов в процессе создания и развития системы органов переселенческого управления. Обозначена динамика и ход развития переселенческой политики в рассматриваемый период. Указаны основные дискуссионные вопросы, связанные с процессом реализации переселенческой политики. Данный период характеризуется глобальными изменениями в процессе проведения миграционной политики по отношению к Сибири во второй половине XIX в., а также появлением нового концептуального геополитического проекта, который ознаменовал собою более высокий уровень взаимодействия в новых для себя политикоэкономических аспектах. В этот период переселенческая политика впервые в своей длительной истории вышла на новый теоретико-дискуссионный уровень, который помог определить ее дальнейшее развитие в рамках внутренней политики. Начало 1880-х гг. стало своего рода отправной точкой в вопросе переселенческой политики, что повлекло за собой активизацию действий со стороны правительства в вопросах ее реализации.
\end{abstract}

Ключевые слова: либеральное направление, колонизационная политика, консервативное направление, переселенцы, система управления, адаптация.

Для цитирования: Попов Е.В. 2021. Характеристика переселенческой политики в Российской империи в 60-80-е гг. XIX в. в контексте дискурса имперских экспертов. Via in tempore. История. Политология, 48 (2): 394-404. DOI: 10.52575/2687-0967-2021-48-2-394-404.

\section{Characteristics of the resettlement policy in the Russian Empire in the $60-80 \mathrm{~s}$ of the 19th century in the context of the discourse of imperial experts}

\author{
Evgeniy V. Popov \\ Omsk State Pedagogical University branch in Tara, \\ 69, Shkolnaya St., Tara, 646530, Russia, \\ E-mail: pve83@inbox.ru
}

\begin{abstract}
This article presents the structure of resettlement management, as well as identifies the main stages of colonization policy from the 60 s to the 80 s. XIX centuries. The main controversial positions of imperial experts in the process of creating and developing a system of resettlement management bodies are outlined. The dynamics and course of development of the resettlement policy in the period under review are indicated. The main controversial issues related to the process of implementing the resettlement policy are indicated. This period is characterized by global changes in the process of the migration policy towards Siberia in the second half of the 19th centuries, as well as the emergence of a new conceptual geopolitical project, which marked a higher level of interaction in new political and economic aspects. During this period, the resettlement policy, for the first time in its long history, reached a new theoretical level of discussion, which helped to further determine its further development within the
\end{abstract}


framework of domestic policy. Early 1880s became a kind of bifurcation points in the issue of resettlement policy, which led to the intensification of actions on the part of the government in the issue of its implementation.

Key words: liberal direction, colonization policy, conservative direction, immigrants, management system, adaptation.

For citation: Popov E.V. 2021. Characteristics of the resettlement policy in the Russian Empire in the 60-80s of the 19th century in the context of the discourse of imperial experts. Via in tempore. History and political science, 48 (2): 394-404 (in Russian). DOI: 10.52575/2687-0967-2021-48-2-394-404.

\section{Введение}

В настоящий момент данная проблематика в исторических исследованиях является одной из самых актуальных, поскольку концентрирует себе сразу несколько исторических проблем второй половины XIX - начала XX вв. Первая проблема - это форма взаимодействия центральной власти и разных территорий Российской империи на примере Сибири; вторая - соотношение внутренней и внешней политики при решении разных политических, экономических задач; третья - переселенческая политика как вариант решения острых социально-экономических и иных задач; четвертая - анализ опыта взаимодействия разных этнических и социальных групп в контексте переселенческой политики. Анализ сложившейся исторической ситуации поможет определить основные задачи при столкновении с подобным в будущем, поскольку для современной России остается актуальной проблема малонаселенности, миграционной политики, а также проблема взаимодействия центральных властей с региональными.

\section{Объекты и методы исследования}

Объектом изучения является переселенческая политика в контексте дискурса имперских экспертов в 60-80-е гг. XIX в., поскольку именно в этот период во многом складываются основные политические и экономические направления в решении данного вопроса. Здесь столкнулось сразу несколько политических лагерей, которые представляли свои планы развития переселенческой политики как инструмента, с помощью которого можно было решить внутренние проблемы. Для написания работы использовались следующие методы: общенаучные (анализ, синтез, дедукция, индукция) и историкосравнительные, историко-генетические. В статье использованы опубликованные источники трех периодов: дореволюционного, советского и современного российского, которые помогли отследить все изменения, касающиеся предмета исследования.

\section{Результаты и их обсуждение}

В период развития Российской империи в XIX в. шел процесс трансформации во многих ее сферах, особенно во внутренней политике. Исторически накопившиеся проблемы нуждались в решениях, что, в свою очередь, заставляло государство изменить вектор внутреннего развития в политическом и экономическом аспекте. Переселенческая политика в отношении Сибири была попыткой решения внутренних проблем.

Подход к проведению политики по отношению к Сибири был основан на геополитическом положении этого региона, а все остальные выступали в фарватере. Изменения в подходах со временем были связаны не только с внутренними причинами, но и с постепенной эволюцией в самих методах работы государства с давно приобретенными территориями. Данная динамика изменений стала тенденцией, что по-разному проявлялось во внутренней политике, а также нашло свое отражение в колонизационной деятельности.

Основная деятельность по проведению колонизационной политики государством была проведена в 80-е гг. XIX в., а вот финансовая и техническая сторона вопроса разра- 
батывалась на протяжении всего развития переселенческой политики. Два этих компонента были главными и спорными моментами в осуществлении всей колонизационной политики в отношении Сибири.

Период колонизационной политики в отечественной историографии интерпретируется в разных аспектах. Так, например, М.К. Чуркин, В.В. Тихонов выделяют этапы по степени адекватной реакции государства на миграционную мобильность русского крестьянства, другие, как например: Д.Н. Белянин, В.Г. Чернуха, А.В. Ремнев, Н.Г. Суворова, определяют этапы по появлению новых органов управления и влияния их на процессы переселенческой политики. Необходимо дать четкое понимание самого процесса переселенческой политики, что это было. Так, по мнению А. Эткинда, данная политика больше напоминала продолжение этапа «внутренней колонизации» (самоколонизации), когда колонизирующие группы населения направлялись на новые территории [Эткинд, 2016].

Важно отметить, что переселенческая политика отражала в себе один из самых динамичных периодов русской истории и охватила собой время с начала $60-\mathrm{x} \mathrm{гг.} \mathrm{XX} \mathrm{в.} \mathrm{до}$ окончания периода развития самой Российской империи. При этом цели и задачи переселенческой политики соответственно менялись в зависимости от внутренних обстоятельств и тех людей, которые стояли в качестве руководителей и исполнителей этого глобального внутреннего проекта.

Характеризуя колонизационную политику, можно выделить сразу несколько направлений в общественно-политической дискуссии, которая интенсивно шла на разных этажах российского общества. Существовало несколько направлений в решении переселенческого вопроса: первое, консервативное, которое в вопросах решения переселенческого проекта на протяжении всего периода колонизационной политики эволюционировало от охранительного подхода до отчасти либерального; второе, либеральное, сразу настаивало на больших и реальных шагах в сторону переселенческой политики и осуществлении ее повсеместно; третье, национально-консервативное, наиболее радикальное, которое ставило перед собой задачи по формированию населения русской идентификации и реализации за счет колонизационной политики только внешнеполитических задач, где основную роль должно было играть казачество, но никак не русское крестьянство.

Так, например, министр народного просвещения А.В. Головин говорил о том, что Сибирь, подобно другим территориям России, а также в отличие от Польши и Финляндии, обладает рядом особенностей, но при этом это, конечно, одна из составных частей современной России. Примерно в таком же ключе выступил М.И. Венюков, который утверждал, что Сибирь - это не мятежный регион, а простое продолжение огромной империи [Венюков, 1877].

Окончательное мнение национал-консерваторов по вопросу о роли Сибири, ее статусе было сформировано к 1880-м гг. и сводилось к идеологии, что «Сибирь - это не колония, а существенная часть России» [Русский вестник, 1833].

Поскольку национал-консерваторы и консерваторы были близки по своим политическим и иным взглядам, а в правительственных кругах в основном на них опирались, не было ничего удивительного, что весь набор механизмов и инструментов на первом этапе колонизационной политики полностью совпадал с этими политическими воззрениями. Имперский проект на первом этапе только отчасти напоминал собой правильно структурированную программу действий, наоборот, государственные деятели практически ничего не предлагали, чтобы что-то предпринимать в содействии русскому крестьянину, и практически полностью игнорировали любую экономическую помощь ему [Ставровский, 1906].

С течением времени состав действующих лиц, осуществляющих колонизационную политику, менялся, параллельно ухудшалась внутриполитическая ситуация в экономическом сегменте. Все также остро стояла проблема малоземелья русского крестьянина в ев- 
ропейской части России, а вопросы внешнеполитической безопасности чаще выходили на первый план.

Консервативное представительство в правительстве в рассматриваемый период всячески пыталось сдержать активную переселенческую политику, об этом писали Я.Ф. Ставровский и В.В. Алексеев, они этот период охарактеризовали как «отрицательносдерживательный» [Ставровский, 1906].

В 80-е гг. XIX в. наступила более активная фаза переселенческой политики со стороны государства, и это изменение связано было напрямую с увеличением переселенческого движения, Так, если в 1877-1881 гг. из Полтавской губернии в Сибирь направлялось лишь 2,2 \% переселявшихся, то в 1887-1891 гг. уже 17,3\%, а в 1892-1893 гг. вообще 70,6 \% [Ставровский, 1906].

В результате правительству пришлось уйти от идеи имперских воззрений и перейти к выработке конкретных реальных программ и механизмов по реализации колонизационной политики. Имперский проект изначально учитывал геополитические задачи, что проявилось в попытке объединить переселенческий и военный аспект в одной большой стратегической задаче. Представитель Генерального штаба полковник Л.М. Болховитинов считал, что необходимо выселять крестьян из малоземельных губерний и ими заселять пустующие окраины, это помогло бы освоить и закрепить новые территории [Барыкина, 2015].

Главноуправляющий землеустройством и земледелием князь Б.А. Васильчиков призывал заменить переселение на заселение, поскольку государству надо было решать геополитические задачи, особенно это касалось дальневосточных земель. С течением времени эта проблема стала еще более актуальной, особенно после оживления внешней политики Китая и в войне с Японией. Перед государством стояла важная задача навести порядок и контроль на колонизируемых территориях, поскольку не все сибиряки были довольны новыми мигрантами и тяготели в своем сознании к более консервативной поведенческой модели. Проблема движения мигрантов на территории малых народов вызывала недовольство со стороны местных этнических групп [Романов, Л. 113].

Н.Д. Облеухов полагал, что, когда русские переселенцы отправляются в Сибирь, «они приносят пользу не только себе и своим семьям, но и также государству, закрепляя своим переселением эту территорию за Российским государством» [Романов, Л. 113].

Мысль, что переселение - это еще инструмент внешней политики, который можно использовать для закрепления и обороны своих территорий, находила отражение в идеях П.А. Столыпина, отмечавшего в 1908 г., что дело государственной обороны затрагивало не только Морское и Военное министерства, но и переселенческое ведомство, «так как должен быть создан на Дальнем Востоке оплот из живых людей» [Барыкина, 2015].

В результате внешнеполитическая задача в имперском проекте выражалась в том, что необходимо было закрепить территории Сибири и Дальнего Востока с помощью активной переселенческой политики, а также построением на этой территории определенной инфраструктуры.

Одно из основных политических направлений этого периода в вопросе принятия решения в колонизационной политике было консервативное. Консервативное направление в основном было представлено правительственными кругами, дворянством и военными, именно они долгое время практически полностью тормозили процесс заселения и освоения Сибири, а в качестве субъекта колонизации практически вообще не видели русского крестьянина, наоборот, в нем они представляли определенную опасность для развития России.

Данное политическое направление было неоднородным по своему составу, это проявлялось в палитре политических и экономических воззрений, которые оказывали воздействие на проведение колонизационной политики по отношению к Сибири. 
Так, например, М.Н. Катков считал переселение средством усиления государственных задач: туда, где было мало русского элемента, необходимо было его дополнительно отправлять [Вельяминов, 1994].

Ф. Бродель полагал, что Сибирь - это отсталый регион и ему не стать ни Америкой, ни Канадой, соответственно государство предпочтет иные формы его освоения, более простые. При этом, учитывая колоссальные богатства Сибири, правительство сделает ставку на имперские проекты, а регион станет транзитной дорогой для будущих переселенцев [Бродель, 1992].

До определенного момента, в частности до строительства Великой железной дороги, Сибирь действительно никак не проявляла свой богатый экономический потенциал. На протяжении практически всего XIX в. Сибирь отставала в своем развитии от основной части России; подобная тенденция сохранялась до 90-х гг. XIX вв., ее можно было охарактеризовать как «географический труп» [Барыкина, 2015].

Переселенческая политика как элемент имперского проекта могла дать России и Сибири новые перспективы развития. Д. Ливен считал, что сибиряки могли бы получить свободу, а также определенное представительство в региональных институтах, что, в свою очередь, выработало бы идеи регионального патриотизма [Русский Век, 1861].

С другой стороны, в имперских проектах никогда не учитывались механизмы и инструментарии, которые могли дать сколько-нибудь правовой свободы и независимости от политического центра. Последнее было исключено, поскольку это никак не вписывалось в построение государственного политического монополизма. В колонизационном аспекте к Сибири как к региону, который мог решить много внутренних проблем в России, относились скептически, не только потому, что боялись внутренних потрясений и проблем с дворянством или геополитического краха этой политики, а просто в этом регионе не видели потенциала - ни экономического, ни политического.

Еще в начале 1861 г. министр императорского двора Е.К. Мейендорф высказал определенное сомнение по поводу начала колонизационной политики. На его взгляд, «новые приобретения больше отнимают сил, ресурсов и людей, которые тратят свои усилия для устройства жизни на новых территориях, однако опасность заключается в другом чем быстрее мы их обустроим, тем больше возможностей у новых окраин от нас отделиться возникнет» [Вельяминов, 1994].

Это мнение было не единичным по своему смыслу и значению, почти так же высказывался М.И. Венюков, который полагал, что большая часть территории Сибири вообще не пригодна для жизни и земледелия. Данные позиции достаточно точно определил председатель политико-экономического комитета В.П. Безобразов, считая, что такое количество противоположных мнений принесет переселенческому делу только противоречивые тенденции, что в дальнейшем отразилось на колонизационной политике [Русский Век, 1861].

При этом среди правительственных экспертов неоднозначно было мнение о роли переселенческой политики в контексте имперского проекта. Г.К. Гинс считал, что у колонизационной политики должно быть культурное воздействие на «незаселенные или слабозаселенные пространства» [Гинс, 1913].

Несмотря на острые политические споры со стороны разных общественнополитических кругов, постепенно формируется структура управления переселенческим делом. Всей совокупностью дел переселенческой политики занималось три ведомства: Министерство внутренних дел, Министерство финансов и Министерство государственных имуществ, а также Главный комитет об устройстве сельского населения. С течением времени правительство создало сразу несколько специальных учреждений - это высшие комитеты для решения чрезвычайных задач. Основным органом стал Главный комитет, его задача заключалась в сдерживании и концентрации действий, направленных на какое- 
либо правовое изменение данного вопроса, и выполнение всех действий правительства в этом направлении осуществлялось именно через этот орган [Романов, Л. 113].

Переселенческая политика и соответствующие органы управления в данной сфере отдельно не выделялись, весь процесс осуществлялся в совокупности с другими отделами. Так, например, в 4-м отделе крестьяне получали право на миграционную деятельность, а в 6-м отделе оформляли документы, связанные с землеустройством, в 8-м отделе работа концентрировалась на инородцах и их землеустройстве в Сибири [Лебедева, 210].

Переселенческая политика проходит в своем развитии несколько этапов: первый характеризуется изданием положения от 19 февраля 1861 г., в котором был сформулирован новый тип социальных отношений между дворянством и крестьянами, а также определена граница, когда крестьянин мог уйти от помещика; второй этап этого периода - это неурожай и голод 1867-1868 гг., который подстегнул к стихийному переселению крестьян, несмотря на существующие запреты. При этом государство попыталось помочь крестьянам благотворительными акциями, комиссию по их реализации лично возглавил наследник престола Александр Александрович, вплоть до конца 1868 г. был потрачен весь фонд собранных и выделенных средств, и, наконец, правительство было вынуждено обратить внимание в этот период на активизацию стихийного переселенческого движения. В 1870 г. закончился 9-летний срок, когда крестьянин мог отказаться от надела, сенатор К.Н Лебедев испытывал опасения по этому поводу, поскольку государство теперь получит еще больше недоимок [Русский Век, 1861].

Два первых этапа характеризуются как сдерживающие, и в них практически нет каких-либо законодательных инициатив в переселенческом вопросе.

Третий этап этого периода начинался с отставки П.А. Валуева, который никак себя не проявил на посту министра внутренних дел, он не смог сформировать какой-либо стратегии в контексте решения переселенческого вопроса, а самое главное - достаточно плохо себя показал своим бездействием во время голода 1868 г. На смену П.А. Валуеву пришел А.Е. Тимашев, однако он сразу, практически с ходу подписал циркуляр, который попал в ряды крестьянства, как «ракетой в стадо баранов» (по выражению управляющего Канцелярией МВД Л. С. Макова) [Барыкина, 2015].

Л.С. Маков достаточно критично оценил этот циркуляр в своем письме бывшему министру П.А. Валуеву; так, на его взгляд, само переселение по себе - это процесс, который требует обсуждения, при этом он прекрасно понимает, что есть свободные земли в Оренбургской и Самарской губерниях, и их можно осваивать путем заселения, однако это не главное в этом вопросе, а вот то, что данная ситуация стала известна всем путем публикации данного циркуляра «Северной почтой», вызывала у него определенный скепсис, поскольку он считал, что информация циркуляра должна была остаться только на уровне правительства [Кирьяков, 134].

Этот циркуляр отчасти дал определенную надежду крестьянству, что чиновничья бюрократическая машина и государство пересмотрит свое отношение к ним. Постепенное накопление информации в виде писем о начале процесса переселений заставило Министерство внутренних дел принимать более активные действия, направленные на сдерживание миграционной активности со стороны русского населения. В 1868 г. вышел второй циркуляр, в котором было заявлено на уровне Министерства внутренних дел о создании комиссии под председательством кн. А.М. Дондукова-Корсакова для работы с переселенцами [Кирьяков, 134].

На четвертом этапе в рассматриваемый период развития переселенческой политики была образована переселенческая комиссия Дондукова-Корсакова (24 июля 1868 г. 23 января 1869 г.). Этот опыт создания подобных комиссий на примере А.А. ДондуковаКорсакова помог приобрести бесценный опыт по работе с переселенцами [Чернуха, 1982].

В этот период развернулась особенно оживленная дискуссия среди чиновников, которые каким-либо образом имели отношение к переселенческой политике; настроение их 
было паническое и окутано страхом перед массовыми переселенческими движениями. П.А. Шувалов в письме от 28 июня 1869 г. прибалтийскому генерал-губернатору П.П. Альбединскому объяснил страх правительства перед массовыми переселениями следующим образом: «Вопрос чрезвычайно трудный... для переселения крестьян в больших размерах у нас не имеется достаточно финансовых и, кажется, даже нравственных сил... главное: весьма опасно показать крестьянам внутренних губерний, что производятся какие-либо переселения под казённою фирмою...» [Валк, 1951].

Комиссия Дондукова-Корсакова не приняла какого-либо закона или циркуляра в сфере переселенческой политики, ограничилась только изданием рекомендаций уже существовавших к этому моменту правил. Новый министр внутренних дел в этот период А.Е. Тимашев предложил новый черновой проект правил переселений, который представил в Главный комитет об устройстве сельского населения [Христофоров, 2011].

Данный документ был переработан и принят, в нем фиксировались подробные правила переселений на все случаи, которые могли быть на практике. Эти правила касались только тех крестьян, которым уже было предоставлено право на переселение, в частности мелкопоместных крестьян, горнозаводских, мастеровых, батраков и бобылей отдельных губерний [Валк, 1951].

Данный список имеющих право на переселение был неполным, при определенном согласии со стороны Министерства внутренних дел и Министерства государственного имущества он мог быть дополнен новыми категориями населения. При этом важно понимать, что данные обстоятельства возникали только в случае особых соображений правительства, которые только на деле могли оказать улучшающее воздействие на хозяйственную деятельность в Сибири [Худяков, 1986].

В дальнейшем Главный комитет сконцентрировал свою деятельность на обустройстве сельского населения, создавал благоприятные условия для улучшения положения переселенцев. Так, например, 28 мая 1870 г. впервые в истории переселенческого дела Комитет утвердил льготы переселенцам [Валк, 1951].

Это был первый шаг в сторону переселенческой политики, носил еще эксклюзивный характер и в большей степени был скорее всего исключением из правила, чем правилом.

Последней этап этого периода в сфере развития переселенческой политики в 1870 1880-е гг. начался после 1878 г. В правительстве был поставлен вопрос пополнения казны, и тут же, практически сразу, решили обратить внимание на крестьян. Поскольку именно русское крестьянство приносило самые существенные доходы в казну, поэтому в этот раз правительство в разных проектах подразумевало раздачу казенных земель, чтобы увеличить количество налогоплательщиков в стране, для этого необходимо было получить согласие сразу двух министров: с одной стороны, Министерства внутренних дел, с другой Министерства государственного имущества. На этот проект о сдаче казенных земель крестьянам оба министерства выступили против, поскольку продолжали в основном опираться на консервативные круги как в правительстве, так и в обществе [Чернуха, 1982].

В 1879 г. данная тенденция на охранительно-консервативную позицию по отношению к переселенческой политике была подтверждена новым циркуляром министра внутренних дел Л.С. Макова, в котором тот четко фиксировал запрет на переселения. При этом буквально тут же вышел еще один важный документ Министерства государственного имущества, который практически ничем не отличался от подобного документа Министерства внутренних дел [Худяков, 1986].

Одним из первых, кто решил пойти на определенные уступки в вопросе переселенческой политики, стало Министерство государственного имущества, что было совсем не случайно - именно оно практически полностью курировало весь спектр колонизационной политики. П.А. Валуев достаточно скептически относился к попытке первых шагов в сфере колонизационной политики; он считал, что необходимо подойти к вопросу о возмож- 
ности переселения крестьян в отдаленные места очень осторожно и, кроме этого, получить первые результаты переселений крестьян для того, чтобы оценить, насколько их возможно в дальнейшим либо возобновить, либо вовсе остановить [Худяков, 1986].

К этому времени среди имперских специалистов в вопросе переселенческой политики наступил определенный консенсус по ряду вопросов. Впервые на уровне правительства за право начать разработку специального закона о переселениях выступил министр финансов Н.Г. Бунге в 1880 г. Во многом это произошло вопреки, а не благодаря. Это означало законодательное оформление закона от 10 июля 1881 г., однако его применение носило временный и секретный характер [Худяков, 1986].

Данный закон применялся только к тем категориям населения, которые засвидетельствовали свою неплатежеспособность, а также должны были получить разрешение на переселение от двух ведомств: Министерства внутренних дел и Министерства государственных имуществ. Временные правила от 10 июля 1881 г. были опубликованы лишь в 1889 г. в Полном собрании законов, при этом территориальное действие этого закона расширялось за счет сибирской земли. Проекты по реализации переселенческой политики в этот период не были осуществлены по разным причинам, данный процесс растянулся на долгие десятилетия [Кирьяков, 1902].

В 1886 г. либеральный курс в лице Н.Г. Бунге был свернут, он ушел в отставку, вместе с ним потерпели крах фритредерские идеи. В Европе в этот период произошел процесс осмысления земли не просто как товара, а как «универсального блага», подобно воздуху и воде. В России наоборот рыночные идеи почти все были свернуты в отношении землевладения [Чернуха, 1982].

Таким образом, большинство законов, которые государство выпустило в период 70-х гг. XIX в., отчасти касались переселенческой политики, имели отношение уже к ней как постфактум к переселившимся мигрантам, жившим на новых территориях. Попытка объединить под руководством кохановской комиссии все основные элементы, занимающиеся переселенческим делом, в частности административные учреждения и общественное управления, с целью уменьшения числа чиновников и сокращения формальностей, а также для установления более тесной связи между государственной системой управления и обществом оказалась в этот период безуспешной. В 1881 г. появилось совещание «сведущих лиц из общества», лиц, которые в разной степени были знакомы с проблемами в переселенческом деле. На практике эти два органа - совещание и комиссия - расходились в своих интерпретациях о механизмах работы основных административных структур, занимающихся переселенческой политикой [Русский архив, 1911].

Окончательно эти соображения об объединении вышеуказанных структур завершились в период правления нового министра внутренних дел Д.А. Толстого. Он не считал особо нужным такое объединение, наоборот, полагал, что у государства мало механизмов влияния на местное управление, да и в целом на весь процесс предстоящих преобразований. По мнению Д.А. Толстого, принцип единства должен быть в основе формирования местной власти, а также во всех местных учреждениях, которые, в свою очередь, обязаны сохранять тесную связь с правительством [Барыкина, 2015].

Одно из главных министерств в переселенческой политике - Министерство государственных имуществ - за 1880-е гг. сформировало дополнительные органы, в частности появился переселенческий отряд, в котором действовали переселенческие конторы. В Омске 20 декабря 1883 г. появилось учреждение, которое аккумулировало в себе систему управления сразу нескольких областей, а в 1893 г. было разделено на три новых государственных органа [Московские ведомости, 1883].

Создание этой структуры управления позволяло государству выполнять определенный набор функций в развитии переселенческой политики: анализировать природногеографические и природно-климатические условия водворения, структурировать и описывать местные особенности сибирских пространств. 
По существу, именно в период 80-х гг. XIX в. государство впервые в своей истории приступило к реализации переселенческого проекта на новом концептуальном уровне. Данная тенденция сразу же нашла свое отражение на уровне законодательства Российской империи, что проявилось в выходе целого ряда новых правовых документов, регламентирующих на официальном уровне все тот же набор форм и видов государственной поддержки.

Таким образом, анализируя характеристику переселенческой политики в контексте дискурса имперских проектов, мы видим, что вся основная система мер, управленческая структура шли со стороны государства, имперские проекты во многом изначально выстраивались на консервативно-охранительном отношении. Однако под напором внутренних факторов они не сдержали свои позиции и были вынуждены идти в сторону послабления, но при этом сохраняли свой консервативный курс.

C приходом новых людей в правительство в конце XIX вв. кардинально изменилось положение дел в организации переселенческой политики, последним консервативным форпостом оставалось Министерство внутренних дел, которое настаивало на более жестком процессе контроля и регулирования переселений. Однако, несмотря на сдвиг в либеральную сторону в решении переселенческого вопроса, курс на осторожную, чересчур выверенную политику оставался, особенно это проявилось в финансовой помощи переселенцам, которой было недостаточно.

\section{Заключение}

Основными причинами активизации переселенческой политики во второй половине XIX в. стала острая проблема малоземелья, а также резкий демографический рост населения страны, который окончательно обострил аграрный вопрос. Государственная политика от 60-гг. до 80-х гг. XIX в. в рамках имперского проекта во многом эволюционировала, особенно от первоначальных целей и задач. Ее можно свести к следующим положениям: 1) с течением времени под давлением разных внутренних факторов государство смогло выработать адекватную систему управления, мер и сотрудничества с крестьянством как с основным субъектом колонизации в переселенческой политике; 2) государство интегрировало разные структуры управления для реализации мер в рамках переселенческой политики; 3) государственная политика всегда была направлена на качественной эффект от переселенческой политики, а не количественный, поэтому по-особенному относилась к процессу контроля потоков мигрантов в Сибирь; 4) несмотря на выстроенную вертикаль управления переселенческим делом, этой системе не хватало координационного взаимодействия; 5) новый тип интеграции власти и общества, государства и крестьянства был реализован в рамках переселенческой политики в Сибирь; 6) произошло объединение в рамках имперского проекта сообщества экспертов разного уровня и государства по проблемам реализации переселенческой политики; 7) в рамках формирования местных государственных структур для оказания помощи переселенцам правительство впервые продемонстрировало правовую гибкость в построении законодательства и решении поставленных задач.

Таким образом, государство выстроило вертикаль управления переселенческой политикой, однако при этом сохранило в своих руках основные механизмы и инструменты по ее управлению. Правительство практически до конца сохранило консервативный курс выстроенной системы, только более мелкие задачи решались либеральными методами. Имперский проект именно в рамках формирования технического инструментария соединил в себе внутреннюю и внешнеполитическую задачу. Правительство продолжало действовать рационально в реализации переселенческой политики, реагируя на те или иные проблемы постепенно и действуя поступательно. 


\section{Список литературы}

1. Барыкина И.Е. 2015. Переселенческий вопрос и правительственная политика 1860-70-х гг. в работах В.Г. Чернухи. Гуманитарные исследования в Восточной Сибири и на Дальнем Востоке. 2 (32): 162.

2. Бродель Ф. 1992. Время мира. Москва, Изд-во Прогресс, 681.

3. Валк С.Н. 1951. Внутренняя политика царизма в 80-х и начале 90-х гг. История СССР. Россия в период победы и утверждения капитализма (1856-1894). Ч. 1. Социально-экономическая и политическая история. Материалы к обсуждению. Москва, Изд-ва Акад. наук СССР, 927.

4. Вельяминов Н.А. 1994. Воспоминание об императоре Александре III. Российский архив. Москва, Студия ТРИТЭ: Рос. Архив, Вып. V. 234.

5. Венюков М.И. 1877. Россия и Восток: собрание географических и политических статей. Санкт-Петербург, тип. В. Безобразова и К을. 297.

6. Гинс Г.К. 1913. Переселение и колонизация. Санкт-Петербург, типография Ф. Вайсберга и П. Гершунина, Вып. 2. 349.

7. Из записок сенатора К.Н. Лебедева. 1911. Русский архив. Москва, Синодальная типография. 10.672.

8. Кирьяков В.В. 1902. Очерки по истории переселенческого движения в Сибири (в связи с историей заселения Сибири). Москва, тип. лит. т-ва И.Н. Кушнерев и К, 374.

9. Министерство внутренних дел. Исторический очерк. 1902. 1802-1902. СанктПетербург, Издательство: Тип. Министерства внутренних дел, 372.

10. Московские ведомости. 1881. 17 мая: 9-14.

11. Политико-экономический комитет при Императорском Русском географическом обществе (собрание 1 апр. 1861 г.). Век. 1861. Москва, изд-во Проспект, 22: 12-34.

12. Романов В.Ф. Старорежимный чиновник (из личных воспоминаний от школы до эмиграции. 1874-1920 гг.). ГАРФ. Ф. Р-5881 (коллекция отдельных документов белоэмигрантов). Оп. 2. Д. 598. Л. 113.

13. Современная летопись: Гонение на православие в России. Русский вестник. 1883. Санкт-Петербург, Изд-во Унив. тип. (М. Катков), Т. 164: 34-36.

14. Ставровский Я.Ф., Алексеев В.В. 1906. Переселение в Сибирь. Прямое и обратное движение переселенцев семейных, одиноких, на заработки и ходоков. Санкт-Петербург, Изд-во Электротип. Н.Я. Стойковой, Вып. 18. 141.

15. Чернуха В.Г. 1982. Из истории государственных учреждений: Главный комитет об устройстве сельского состояния. 1861-1882 гг. Вспомогательные исторические дисциплины. Ленинград, Академия наук СССР. Т. 13: 14.

16. Христофоров И.А. 2011. Судьба реформы. Русское крестьянство в правительственной политике до и после отмены крепостного права (1830-1890-е гг.). Москва, Собрание, 381.

17. Худяков В.Н. 1986. Аграрная политика царизма в Сибири в пореформенный период. Под ред. Л.М. Горюшкина; Омский гос. пед. ин-т им. А.М. Горького. Томск, Изд-во Том. ун-та, 263.

18. Эткинд А. 2016. Внутренняя колонизация. Имперский опыт России. Москва, Новое литературное обозрение. 448.

\section{References}

1. Barykina I.Ye. 2015. Rasseleniye i gosudarstvennaya politika 1860-70-kh godov v rabotah V.G. CHernuhi [Resettlement and state policy of the 1860s - 70s in the works of V.G. Chernukha]. Gumanitarnye issledovaniya v Vostochnoy Sibiri i na Dal'nem Vostoke [Humanitarian research in Eastern Siberia and the Far East]. 2 (32): 162 (in Russian). 681 (in Russian).

2. Braudel F. 1992. Vremya mira [Time of the world]. Moscow, Progress Publishing House,

3. Valk S.N. 1951. Vnutrennyaya politika tsarizma v 80-kh - nachale 90-kh gg. Istoriya SSSR. Rossiya v period pobedy i utverzhdeniya kapitalizma (1856-1894). Chast' 1 [Internal policy of tsarism in the 80s and early 90s History of the USSR. Russia in the period of the victory and establishment of capitalism (1856-1894). Part 1]. Sotsial'no-ekonomicheskaya i politicheskaya istoriya. Materialy k obsuzhdeniyu [Socio-economic and political history. Materials for discussion]. Publishing house Acad. Moscow, of Sciences of the USSR, 927 (in Russian). 
4. Velyaminov N.A. 1994. Vospominaniya ob imperatore Aleksandre III [Memories of Emperor Alexander III]. Rossiyskiy arkhiv [Russian archive]. Moscow, Studio TRITE: Ros. Archive. V. 234 (in Russian).

5. Venyukov M.I. 1877. Rossiya i Vostok: sbornik geograficheskikh i politicheskikh statey [Russia and the East: Collection of Geographical and Political Articles]. St. Petersburg, a type. V. Bezobrazova and $\mathrm{K}^{\circ} .297$ (in Russian).

6. Hins G.K. 1913. Pereseleniye i kolonizatsiya [Resettlement and colonization]. St. Petersburg, the printing house of F. Weisberg and P. Gershunin, 2. 349 (in Russian).

7. Iz zapisok senatora K.N. Lebedeva [From the notes of Senator K.N. Lebedev]. 1911. Rossiyskiy arkhiv [Russian archive]. Moscow, Synodal Printing House. 10. 672 (in Russian).

8. Kiryakov V.V. 1902. Ocherki istorii pereselencheskogo dvizheniya v Sibiri (v svyazi s istoriyey rasseleniya Sibiri) [Essays on the history of the resettlement movement in Siberia (inconnection with the history of the settlement of Siberia]. Moscow, typ. lit. t-va I.N. Kushnerev and Co, 374 (in Russian).

9. Ministerstvo vnutrennikh del. Istoricheskiy ocherk. 1902. 1802-1902 [Ministry of the Interior. Historical sketch]. St. Petersburg, Type. Ministry of Internal Affairs, 372 (in Russian).

10. Moskovskiye vedomosti [Moskovskie vedomosti]. 1881. Moscow, Newspaper. 17 May: 9-14 (in Russian).

11. Politiko-ekonomicheskiy komitet Imperatorskogo Russkogo geograficheskogo obshchestva (zasedaniye 1 aprelya 1861 g.) Vek. 1861 [Political and Economic Committee of the Imperial Russian Geographical Society (meeting April 1, 1861]. Moscow, publishing house Prospect, 22: 12-34 (in Russian).

12. Romanov V.F. Ofitser starogo rezhima (iz lichnykh vospominaniy ot shkoly do emigratsii. 1874-1920) [Old-regime official (from personal memoirs from school to emigration. 1874-1920)]. GARF. F. R-5881 (collection of individual documents of White emigrants). Op. 2. D. $598: 113$ (in Russian).

13. Sovremennaya letopis': goneniya na Pravoslaviye v Rossii. Rossiyskiy vestnik. 1883. [Modern Chronicle: Persecution of Orthodoxy in Russia. Russian Bulletin]. St. Petersburg, Univ. a type. (M. Katkov), T. 164: 34-36 (in Russian).

14. Stavrovsky Ya.F., Alekseev V.V. 1906. Pereseleniye v Sibir'. Pryamoye i obratnoye peremeshcheniye migrantov, semey, odinokikh, na rabotu i peshekhodov [Resettlement to Siberia. Direct and reverse movement of migrants, family, single, for work and walkers]. St. Petersburg, Electrotype. N. Ya. Stoikova, Vol. 18. 141 (in Russian).

15. Chernukha V.G. 1982. Iz istorii gosudarstvennykh uchrezhdeniy: Glavnyy komitet po ustroystvu sel'skogo gosudarstva. 1861-1882 gg. Vspomogatel'nyye istoricheskiye distsipliny [From the history of state institutions: The main committee on the structure of the rural state. 1861-1882 auxiliary historical disciplines]. Leningrad, of the USSR Academy of Sciences. T. 13: 14 (in Russian).

16. Khristoforov I.A. 2011. Sud'ba reformy. Russkoye krest'yanstvo v gosudarstvennoy politike do i posle otmeny krepostnogo prava (1830-1890-ye gg.) [The fate of the reform. The Russian peasantry in government policy before and after the abolition of serfdom (1830-1890s)]. Moscow, meeting, 381 (in Russian).

17. Khudyakov V.N. 1986. Agrarnaya politika tsarizma v Sibiri v poreformennyy period [Agrarian policy of tsarism in Siberia in the post-reform period. Ed. L.M. Goryushkina]; Omsk state ped. in-t them. A.M. Gorky. Tomsk, Publishing house of Vol. un-that, 263 (in Russian).

18. Etkind A. 2016. Vnutrennyaya kolonizatsiya. Imperatorskiy opyt Rossii [Internal colonization. Imperial experience of Russia]. Moscow, New literary review, 448 (in Russian).

\section{ИНФОРМАЦИЯ ОБ АВТОРЕ}

\footnotetext{
Попов Евгений Викторович, старший преподаватель кафедры гуманитарных дисциплин и правоведения Филиала Омского государственного педагогического университета в г. Тара, Россия
}

\section{INFORMATION ABOUT THE AUTHOR}

Evgeny V. Popov, senior Lecturer of the Department of Humanities and Law of the Branch of the Omsk State Pedagogical University in Tara, Russia 